\title{
O ESTRANGEIRO COMO INIMIGO
}

Heloisa Fernandes Câmara ${ }^{1}$

\section{RESUMO}

A despeito do fato de migrações serem comuns na história, é grande a exclusão que o migrante sofre, exclusão esta que pode ocorrer tanto em termos econômicos, sociais e culturais. Além deste tipo de apartamento, no contexto político, especialmente após os ataques terroristas de 11 de setembro, os migrantes foram fortemente identificados com ameaça à segurança nacional, de forma que institutos jurídicos tidos por consagrados como o asilo - correm o risco de ao esfumaçarem-se perder sua eficácia. $O$ presente trabalho pretende trazer a lógica da relação política amigo-inimigo, de Carl Schmitt, para entender o motivo deste discurso que identifica o migrante ao risco.

\begin{abstract}
Despite the fact migrations are common through history, the exclusion the migrant suffers is considerable, and it may happen economically, socially and culturally. Nother kind of separation, on the political context, specially after the September 11th terrorist attacks, is that migrants are often identified as threats to national security, causing institutes such as the asylum to perish and lose their effectiveness. his article plans to bring the logic of the political relation friend-enemy, by Carl Schmitt, to understand the motives behind this speech that identifies the migrant to the risk.
\end{abstract}

\footnotetext{
${ }_{1}^{1}$ Mestranda em Direito do Estado na Universidade Federal do Paraná. Graduada em Direito UFPR. Bolsista CAPES
}

Revista Brasileira de Direito Internacional, Curitiba, v.8, n.8, jul/dez.2008 


\section{INTRODUÇÃO}

"As águas é que são felizes, não têm que ter visto pra entrar no país" Karnak

$\mathrm{Na}$ contemporaneidade, e mais especificamente após os ataques terroristas de 11 de setembro de 2001, pode-se observar um discurso político que tenta identificar o estrangeiro à ameaça, seja política, econômica ou social. Esse discurso não se circunscreve a um determinado país ou região, ao contrário, pode ser observado tanto em medidas mais severas de política migratória (notadamente as medidas de segurança adotadas em aeroportos dos Estados Unidos e Reino Unido, além de nova legislação adotada pela União Européia), como em ataques contra estrangeiros (como ocorrido recentemente na África do Sul). Embora grande parte do discurso dirija-se aos estrangeiros indocumentados - que reiteradamente são tratados por “imigrantes ilegais", embora não haja ilegalidade, mas infração administrativa também pode ser notado o alcance da identificação com a insegurança de estrangeiros externos, notadamente de islâmicos.

Neste contexto pós 11 de setembro, a primeira identificação do estrangeiro à ameaça ocorreu contra estrangeiros que pudessem ser de origem islâmica, identificados com o risco terrorista. Em um segundo momento, todos os estrangeiros que poderiam representar um risco terrorista e a prevenção dessa ameaça foi a causa oficial da mudança das regras de aviação adotadas em vôos internacionais (e ainda mais restritivas nos que passavam pelos Estados Unidos). Hoje, entretanto, qualquer estrangeiro é visto como uma ameaça em potencial. Não somente ameaça terrorista, mas em última análise econômica e social. Berlusconi, primeiro-ministro italiano, referiu-se aos migrantes como "exercito do mal" que deveria ser combatido por forças do exército. De forma que o estrangeiro é tanto ameaça interna quanto externa, e segundo a lógica fundante deste discurso, os dois aspectos devem ser combatidos com o mesmo rigor.

A busca da identificação do estrangeiro com ameaças ultrapassa a discriminação, ou o não respeito a diferenças, mas está inscrito em uma lógica 
específica. Dessa forma este artigo pretende questionar qual é a lógica com que o discurso de perigo opera e qual o papel dos imigrantes nos problemas apresentados. Também é imprescindível a análise do motivo desta postura ser aceita e difundida. Por fim, apresentaremos algumas das conseqüências da postura de alarme e medo dos migrantes para o campo político e de direitos humanos.

Para subsidiar tais análises dialogaremos com Carl Schmitt - e a noção e importância do conceito de amigo/inimigo, Chantal Mouffe - e a releitura do conceito schmittiano, Zygmunt Bauman - através de sua teoria sobre a incerteza presente na política moderna, além de Giorgio Agamben - sobre campo para migrantes e alguns procedimentos migratórios.

\section{POLÍTICA COMO RELAÇÃO AMIGO/INIMIGO}

Carl Schmitt foi um jurista esquecido durante grande parte do século XX devido à sua ligação com o sistema nazista. Não obstante tal ligação, que ainda hoje é objeto de alguns debates, é um autor com provocações bastante pertinentes ao direito. Sua teoria inverte a tradicional representação do Estado e da política na medida em que considera a prevalência do elemento político sobre o Estado. Invertendo as concepções mais tradicionais, aponta uma anterioridade e superioridade da política frente ao elemento jurídico. Seus questionamentos acerca das insuficiências de um modelo de legalismo e da democracia parlamentar é de fundamental importância para (re)pensarmos o político e a democracia. Todavia abordaremos neste artigo o suas noções sobre a política através do conceito de amigo/inimigo.

No livro $O$ Conceito do Político Schmitt apresenta a relação amigo/inimigo como uma categoria especificamente política. Dessa forma rejeita, ou melhor, é independente de conceitos como bom/mau, belo/feio, útil e prejudicial ou rentável e não rentável ${ }^{2}$. Não se fundamentado em distinções de outros campos, esta relação representa a possibilidade ou não de relações com outros grupos. De forma que o considerado inimigo o é de uma forma

\footnotetext{
${ }^{2}$ SCHMITT, Carl. O Conceito do Político. p. 51.
}

Revista Brasileira de Direito Internacional, Curitiba, v.8, n.8, jul/dez.2008 
relacional, ou seja, no sentido em que uma determinada posição ameaça o agrupamento social (amigo), não sendo uma caracterização absoluta. Não obstante a negação da subordinação do político a quaisquer outros critérios, Schmitt identifica o inimigo como "(...) o outro, o estrangeiro, bastando à sua essência que, num sentido particularmente intensivo, ele seja existencialmente algo outro e estrangeiro, de modo que, no caso extremo, há possibilidade de conflito com ele (...."3.3. Ou seja, há duas possibilidades de interpretação deste trecho: i) Schmitt acredita que o estrangeiro é/pode ser o inimigo. Neste caso, estaria sendo negada a base de sua teoria, qual seja, a especificidade do critério político sobre todos os demais, inclusive os de nacionalidade. ii) Schmitt identifica, discursivamente, a figura do estrangeiro como o do outro, ou seja, aquele que não está incluído na minha comunidade política. Este parece ser o melhor entendimento. E precisamente neste sentido interessa-nos entender porque o estrangeiro é tido como o outro, ou seja, não só que é excluído dos laços políticos, mas mesmo os coloca em risco. Esta questão será examinada no próximo tópico.

O conceito de inimigo é proveniente de uma relação concreta política, o que quer dizer que para ser assim considerado não basta haver uma divergência privada, mas deve ser o inimigo público. Esse inimigo público de alguma maneira coloca em risco a sobrevivência e coesão da comunidade considerada amiga. O amigo é formado como oposição ao inimigo, e viceversa $^{4}$.

Ainda para Schmitt, para que seja de fato inimigo deve haver a possibilidade real de eliminação física. $O$ antagonismo proveniente da relação amigo/inimigo possibilita efetivamente a guerra. Por isso, para ele, a inexistência de possibilidade de guerra é a negação da política.

Chantal Mouffe parte de Schmitt para pensar alguns conceitos presentes em sua obra, como o conflito, de forma a pensar na democracia radical, e, portanto, no elemento político. Todavia partir de Schmitt não significa

\footnotetext{
${ }^{3}$ SCHMITT, Carl. O Conceito do Político. p. 52.

4 "O inimigo é um conjunto de homens, pelo menos eventualmente, isto é, segundo a possibilidade real, combatente, que se contrapõe a um conjunto semelhante." (grifos no original). SCHMITT, Carl. O Conceito do Político. p. 55.
}

Revista Brasileira de Direito Internacional, Curitiba, v.8, n.8, jul/dez.2008 
necessariamente aceitar suas conclusões. Mouffe pretende "(...) pensar com Schmitt, contra Schmitt e utilizar os seus pontos de vista para fortalecer a democracia liberal para os seus críticos" ${ }^{\prime \prime}$. Feitas tais advertências, passamos a analisar as considerações de Mouffe acerca da relação amigo/inimigo.

\subsection{RELAÇÃO AMIGO/INIMIGO PARA CHANTAL MOUFFE}

Para pensar a democracia, e propor como modelo a democracia radical, Mouffe rejeita a idéia da democracia enquanto pacificação e alça o conflito a um dos elementos democráticos mais importantes.

Para ela, na esteira do pensamento de Schmitt, a democracia liberal tende a neutralizar o âmbito político através de instituições que regulam o funcionamento democrático. As discussões e questões controversas são restringidas à esfera privada ${ }^{6}$. Com isso pretende-se reduzir o âmbito conflitivo e antagonístico da política. Mas ao pretender neutralizar a política o que está em jogo é a possibilidade de eliminação da esfera política ${ }^{7}$.

A concepção de fim da história - elaborada por Francis Fukuyama para designar a supremacia da democracia liberal tendo em vista o fim do comunismo - demonstra a tentativa de uma história sem conflitos. E por isso pode parecer contraditório a emergência de diversos conflitos étnicos e religiosos no pós-queda muro de Berlim ${ }^{8}$. A concepção liberal, na busca de uma neutralização, credita tais eventos a um retorno do arcaico, ou então, de forma conveniente, a algum desvio da escala evolutiva da democracia liberal e não consegue perceber que ao ser privada de seu elemento constitutivo, o conflito, a política retorna em forma de uma não-política violenta e com antagonismos não reconhecidos. ${ }^{9}$

\footnotetext{
${ }^{5}$ MOUFFE, Chantal. O Regresso do Político. p. 12-13.

${ }^{6}$ MOUFFE, Chantal. O Regresso do Político. p. 149.

${ }^{7}$ MOUFFE, Chantal. O Regresso do Político. p. 12.

${ }^{8}$ Para citar apenas um exemplo lembraremos a questão conhecida como "Guerra dos Balcãs" em que no coração da Europa os conflitos étnicos que havia sido apaziguados através de uma identidade única comunista, ressurgiram de forma extremamente violenta e originaram situações como campos de estupros de mulheres muçulmanas.

${ }^{9}$ MOUFFE. Chantal. O Regresso do Político. p. 12
} 
Para pensar essa situação Mouffe parte da relação amigo/inimigo e de Schmitt para chegar a respostas distintas das dadas pelo autor alemão. Ela considera que a distinção fundamental da política não é do inimigo, mas a do antagonista. Isto significa que há um conflito, mas neste conflito as duas partes aceitam os pressupostos básicos (democráticos) e divergem em relação a outras questões. Portanto não é a eliminação física que está em jogo (como propõe Schmitt), tampouco a formação de um consenso (como querem os liberais), mas a existência permanente de conflitos, mas que são estabilizados momentaneamente, para logo depois ressurgirem, em um processo permanente de abertura e fechamento. Mas a figura do inimigo não é excluída. O inimigo está presente na relação democrática como aquele que não aceita os pressupostos da relação democrática.

A negação das hostilidades políticas não as elimina, mas as transforma em algo mais do que hostilidade, transforma em um processo de identificação de inimigos a serem combatidos, ao invés de antagonistas participantes de um mesmo conflito político. Pois ainda há necessidade da constituição de um "outro" para garantir unidade ao "nós", ou seja, o elemento externo constitui a identidade de um grupo $^{10}$. Se isso não é feito na esfera política, por seu esvaziamento, é retomado de alguma outra forma, que pode ser a da tentativa de criar inimigos que unifiquem uma identidade.

Esse processo é explicado por Mouffe como a fragmentação da identidade coletiva de democracia/totalitarismo surgida no pós-guerra faz ressurgir conflitos étnicos, religiosos, nacionais e outros. Outra situação é o risco da perda da identidade da democracia, já que não há uma fronteira definida entre o "nós" e o "eles". A dificuldade de encontrar um inimigo que acompanha a esquerda e a direita moderada não ocorre com a extremadireita $^{11}$. Elas já elegeram os emigrantes como o "inimigo interno" a ser

\footnotetext{
${ }^{10}$ Isto significa que para formar uma identidade comum há a necessidade de identificação daqueles que não fazem parte desta identidade e em um processo de negação daquilo que não é constitui-se a identidade comum de um determinado grupo. Logo a necessidade de um outro é fundamental para a existência de um nós. MOUFFE, Chantal. O Regresso do Político. p.13.

${ }_{11} \mathrm{~A}$ impressão é que a esquerda tenta se articular no reconhecimento de inimigos, tais como as grandes corporações e a globalização econômica. Entretanto o discurso é muito mais vago e incerto e por isso muitas vezes desqualificado como insuficiente. O discurso de extrema-
}

Revista Brasileira de Direito Internacional, Curitiba, v.8, n.8, jul/dez.2008 
combatido, por eles prejudicarem uma identidade nacional e a soberania das nações. O que Mouffe defende é que:

(...) o crescimento da extrema-direita em vários países da Europa só pode ser entendido no contexto de uma profunda crise de identidade política que afecta a democracia liberal, na seqüência da perda dos tradicionais marcos políticos. Está ligado à necessidade de redefinir a fronteira política entre amigo e inimigo. ${ }^{12}$

Uma análise similar acerca da ausência da figura do inimigo para contrapor ao amigo é dada pelos autores Giorgio Agamben e Slavoj Žižek. Apesar das diferenças entre as teorias, ambos os autores partem da situação da política e seu progressivo esvaziamento. Portanto oferecem subsídios para pensar as alternativas à tal esvaziamento, assim como oferecerem análises críticas acerca das conseqüências de tal processo.

\subsection{LIMIAR DE INDISTINÇÃO}

O diagnóstico de Agamben para a situação política da modernidade ${ }^{13}$ não é essencialmente distinta da efetuada por Mouffe, embora parta dessa situação para pensar outras questões, como a exceção. Para ele a relação amigo-inimigo não é mais a relação que fundamenta a política. " $A$ dupla categorial fundamental da política ocidental não é aquela amigo-inimigo, mas vida nua-existência política, zoé-bíos, exclusão-inclusão."14 Complementando em outro momento de sua obra: "As distinções políticas tradicionais (como aquelas entre direita e esquerda, liberalismo e totalitarismo, privado e público) perdem sua clareza e sua inteligibilidade, entrando em uma zona de

direita, ao contrário, ao indicar um rosto como inimigo, o do estrangeiro de forma geral, cria uma maior concretude na identificação do inimigo a ser combatido. Alertamos que embora Mouffe coloque a questão utilizando a separação entre esquerda e direita, outros autores analisados - como, por exemplo, Agamben - consideram que não há mais tal distinção, subsistindo como distinção fundamental na política a relação vida nua/vida política.

12 MOUFFE, Chantal. O Regresso do Político. p. 14.

13 "(...) justamente no instante em que [a democracia] parecia haver definitivamente triunfado sobre seus adversários e atingido seu apogeu, ela se revelou inesperadamente incapaz de salvar de uma ruína sem precedente aquela zoé a cuja liberação e felicidade havia dedicado todos seus esforços (...)". AGAMBEN, Giorgio. Homo Sacer: o poder soberano e a vida nua. p. 17.

${ }^{14}$ AGAMBEN, Giorgio. Homo Sacer: o poder soberano e a vida nua. p. 16.

Revista Brasileira de Direito Internacional, Curitiba, v.8, n.8, jul/dez.2008 
indeterminação logo que o seu referente fundamental tenha se tornado a vida nua." ${ }^{15}$

Agamben parte da análise da vida nua, ou seja, a pura vida biológica do vivente, para concluir que a política moderna a incluiu em seu funcionamento (em oposição à política grega, em que era excluída). Todavia, o que nos interessa nesse momento é o mesmo diagnóstico da política, ou seja, da dificuldade (ou para ele impossibilidade) de estabelecer distinções políticas. Todas as categorias apresentam-se indistintas, e a política mostra-se como privada de sua forma de funcionamento. Neste contexto que ele explica os eventos modernos, inclusive a situação do racismo na Sérvia, com a limpeza étnica, e o renascimento do fascismo na Europa ${ }^{16}$.

Ele e Mouffe parecem ver o mesmo panorama de desintegração do espaço político e da política e a emergência de conflitos julgados já superados.

Žižek, por sua vez, acompanha Agamben na análise de indistinção de categorias políticas clássicas. Se Schmitt falava de guerra como uma possibilidade efetiva na relação com o inimigo, para Žižek, a diferença entre paz e guerra está embaçada, pois para ele "estamos entrando numa era em que um estado de paz em si pode ao mesmo tempo ser um estado de emergência ${ }^{17 . "}$

Sua análise da relação amigo/inimigo é que esta nunca é apenas uma representação de uma diferença factual: o inimigo é até certo ponto invisível, não pode ser reconhecido diretamente - e por isso o grande problema ou tarefa da luta política é oferecer ou construir uma imagem reconhecível do inimigo. ${ }^{18}$ Prossegue ainda dizendo que "o 'reconhecimento do inimigo' é sempre uma atividade performativa que, ao contrário das aparências enganosas, traz à luz ou constrói o 'verdadeiro rosto' do inimigo. (...) para reconhecer o inimigo (...) é necessário 'esquematizar' a figura lógica do Inimigo,

\footnotetext{
${ }^{15}$ AGAMBEN, Giorgio. Homo Sacer: o poder soberano e a vida nua. p. 128.

${ }^{16}$ AGAMBEN, Giorgio. Homo Sacer: o poder soberano e a vida nua. p. 128.

17 ŽIŽEK, Slavoj. Bem vindo ao Deserto do Real! cinco ensaios sobre o 11 de setembro e datas relacionadas. p. 128.

${ }^{18}$ ŽIŽEK, Slavoj. Bem vindo ao Deserto do Real! cinco ensaios sobre o 11 de setembro e datas relacionadas. p. 130.
} 
provendo-a de características tangíveis concretas que a transformem num alvo adequado de ódio e de luta"19.

Ou seja, a construção de um inimigo concreto e facilmente encontrável - os migrantes ou os estrangeiros de uma forma geral - tem por conseqüência a construção da própria identidade social, que devido ao declínio da política tem sido cada vez mais difícil de ser identificada. Os atentados terroristas, e a comoção gerada, forneceram uma boa ocasião para a criação de um inimigo. $\mathrm{O}$ fato dos riscos e da insegurança sofrida não ser proveniente de fatos passíveis de imputação aos estrangeiros é um mero detalhe que não foi considerado nos discursos e nas políticas de imigração.

\section{O ESTRANGEIRO}

A figura do estrangeiro, por definição, mostra um estranhamento, explicita uma distância entre culturas que é difícil de superar. A origem do termo mostra que esta característica está no cerne do significado. A palavra é proveniente do termo francês (antigo) estrangier (atual étranger), que por sua vez origina-se da palavra francófona estrange (atual étrange), derivada do termo latino extraneus, 'estranho'. ${ }^{20}$ A mesma sensação de afastamento também pode ser encontrado no termo "bárbaro" que significa além de estrangeiro e cruel, desumano. Este termo originou-se devido a ausência de entendimento dos povos ditos civilizados ao ouvirem a língua dos povos estrangeiros. Como parecia uma grande onomatopéia, o termo foi cunhado para designar o barulho feito por estes estrangeiros ${ }^{21}$. Sem uma linguagem (entendida como uma cultura) comum, não restava outra designação além da feita pela oposição aos seres civilizados.

\footnotetext{
${ }^{19}$ ŽIŽEK, Slavoj. Bem vindo ao Deserto do Real! cinco ensaios sobre o 11 de setembro e datas relacionadas. p. 130.

${ }^{20}$ Novo Dicionário Eletrônico Aurélio versão 5.11, 2004.

21 "Ele [guia para peregrinos de Compostela no século XIII] aconselha: passai por tal estrada, não deixeis, principalmente, de visitar tal santuário, onde estão depositadas relíquias milagrosas, mas, quando tiverdes ultrapassado Bordes, caireis num país, o país basco, onde as pessoas não falam mais como humanos, latem como cães". DUBY, Georges. Ano 1000, ano 2000: na pista de nossos medos. p. 62.
}

Revista Brasileira de Direito Internacional, Curitiba, v.8, n.8, jul/dez.2008 
A origem - ou poderíamos dizer a desconstrução - dos termos mostra que o estrangeiro sempre foi entendido como o outro por excelência, aquele que não compartilha dos mesmos valores. Não por outro motivo, quando se pretende demonstrar a sensação de alheamento usa-se a comparação com o estrangeiro $^{22}$.

Somado ao estranhamento presente no âmago do termo estrangeiro, há também o fato de que nossa era presencia uma migração sem precedentes. O que existe hoje são dois movimentos que fazem com que massas enormes de pessoas tenham que migrar. De um lado há as migrações forçadas representada principalmente pelos refugiados e deslocados internos. ${ }^{23}$ Como Hannah Arendt aponta no livro Origens do Totalitarismo, o momento pós guerra criou uma multidão de apátridas e refugiados, e como nenhum país estava preparado para recebê-los (os instrumentos jurídicos eram utilizados para indivíduos e não grupos) a única opção para eles eram os campos. De outro lado, além dos migrantes forçados, há os migrantes que fogem de situação de miserabilidade e buscam ingressar nos países mais desenvolvidos (os Estados Unidos e a União Européia são os maiores exemplos). De forma que a junção desses dois eventos geradores de migrantes faz com que exista uma quantidade enorme de migrantes nos países desenvolvidos - ou para alguns uma invasão bárbara.

A grande quantidade de migrantes aliada à sensação de estranhamento torna-os aptos a serem a face construída do inimigo, ou seja, de serem culpados pelos problemas políticos. Todavia, cabe analisarmos em

\footnotetext{
${ }^{22}$ Albert Camus, em seu livro O Estrangeiro, mostra exatamente essa sensação. A história é sobre Meursault, um operário, que no começo do livro ao descobrir que sua mãe havia morrido vai ao velório e não esboça nenhum sentimento. Um dia passeia com um amigo e sem nenhum motivo mata um árabe (por causa do sol que incomodava seus olhos). É condenado à morte, e a decisão apóia-se, entre outros fatores, na indiferença em relação à morte da mãe como sinal de que ele já carregava a morte no coração. A obra pretende falar do absurdo. O título permite questionarmos quem é o estrangeiro. Se o árabe assassinado por Mersault, ou ele mesmo, pois ainda que nacional não compartilha dos valores sociais, mantendo-se em uma apatia que o torna estranho ao seu meio. Neste sentido poderíamos chegar à conclusão que em um mundo absurdo, os estrangeiros somos nós, independente de onde estejamos. CAMUS, Albert. L'etranger.

${ }^{23}$ Figura que no direito internacional designa pessoas que têm que abandonar suas casas, mas ficam no mesmo país. Também conhecidos como "refugiados internos".
}

Revista Brasileira de Direito Internacional, Curitiba, v.8, n.8, jul/dez.2008 
que medida esses migrantes podem ser considerados como os culpados pelos problemas enfrentados pelos países do chamado primeiro mundo.

\subsection{BREVES CONSIDERAÇÕES ACERCA DAS MIGRAÇÕES E SEUS "RISCOS"}

Migração é um evento natural da humanidade. Normalmente é motivado por necessidade, seja a existência de guerras na região de origem, seja eventos naturais ou perseguição política, há vários motivos que fazem com que as pessoas resolvam abandonar suas origens, seu mundo conhecido, para partir para uma rota incerta. Alguns países foram formados pela contribuição de migrantes, como os Estados Unidos, e outros como o Brasil, em um determinado momento acolheram migrantes que contribuíram decisivamente para a construção das características nacionais.

Portanto, a grande questão é o porquê vemos os migrantes como uma ameaça. Primeiramente, os nacionais atribuem as crises e recessões à existência de migrantes. Mas esse raciocínio em geral não merece prosperar por alguns motivos. O primeiro é que a existência de recessões econômicas têm a mesma origem na criação de migrantes. Com a globalização as distâncias entre os mais ricos e mais pobres tende a aumentar, criando multidões de miseráveis que não encontram em sua terra a possibilidade de sobrevivência digna ${ }^{24}$. A crise nos países desenvolvidos não é causada pelos migrantes, mas tem a mesma causa da criação dos migrantes. A identificação dessas pessoas com motivos de crise esbarra em algumas outras questões. Uma delas é o envelhecimento populacional que atinge alguns países, criando

\footnotetext{
${ }^{24}$ Os eventos recentes ocorridos na África do Sul parecem demonstrar como a situação política pode ser imputada a grupos que não são os causadores dos problemas. Houve ataques violentos - que culminaram com várias mortes - à populações refugiadas que viviam neste país por terem sido consideradas culpadas dos problemas econômicos enfrentados em várias comunidades. Todavia um olhar mais atento certamente lembrará dos muitos problemas causados pelo apartheid que durante décadas excluiu os negros de qualquer participação na vida política e econômica do país. Embora tenha acabado enquanto regime, há um enorme abismo entre a população negra e a população branca, e que não parece disposto a recuar. Desta maneira, creditar a miserabilidade aos refugiados parece uma saída tão conveniente quanto ineficaz.
}

Revista Brasileira de Direito Internacional, Curitiba, v.8, n.8, jul/dez.2008 
uma demanda de trabalhadores, que na insuficiência dos nacionais em supri-la pode ser feito pelos estrangeiros ${ }^{25}$.

A questão cultural é mais difícil de ser rebatida, em geral porque expressa uma concepção racista de cultura, a qual considera que a cultura deve ser "pura" ${ }^{26}$. Não é razoável pensar que os imigrantes colocarão os símbolos nacionais em risco, o máximo que podem fazer é acrescentar alguns ingredientes culturais. Mas esse argumento é particularmente interessante porque na defesa da globalização um dos aspectos exaltados é a "troca cultural”. O conceito da aldeia global. Ou seja, nos outros países o recebimento de produtos estrangeiros é celebrado como uma troca, mas nos países centrais a cultura deve permanecer pura e as outras culturas devem ser apreciadas como elementos exóticos, de preferências em museus ou em canais pagos.

Outro ponto abordado no discurso xenófobo é que eles trazem insegurança e que seriam responsáveis pela elevação de crimes. Esse argumento foi apropriado na histeria causada pelo 11 de setembro para fazer com que eles fossem identificados aos terroristas. Embora os autores dos atos terroristas tenham sido estrangeiros, eles não imigraram em busca de emprego, ou de nova condição de vida, mas como estratégia de um plano deliberado. Cabe lembrar que o atentado de Oklaroma também inicialmente foi creditado a fundamentalistas islâmicos. Depois foi descoberto tratar-se de um cidadão norte-americano.

O terrorismo tem por princípio semear o medo através de ações inesperadas e chocantes (neste sentido uma imagem reprisada infindas vezes é o ideal máximo do terror). O terrorismo não é ligado a Estados, e essa é a grande questão que dificulta seu combate. Por isso parece pelo menos temerário identificar o terrorismo com estrangeiros ou ver em todos os estrangeiros um terrorista em potencial.

\footnotetext{
${ }^{25}$ A dependência dos países desenvolvidos do trabalho desempenhado por migrantes serviu de mote para o filme "Um Dia sem Mexicanos" (2004) em que se simula como seria um dia na Califórnia sem os mexicanos. Ao tomarmos conhecimento que $1 / 3$ da população ativa deste estado é de mexicanos pode-se imaginar as grandes confusões retratadas na comédia.

${ }^{26}$ Embora a discussão do conceito de cultura pura - e mesmo sua possibilidade - ultrapassem muito o objetivo deste trabalho não podemos deixar de notar que a construção da Europa e de várias de suas características - como a própria ciência - deveu-se principalmente às trocas com os estrangeiros, mesmo nos momentos em que era invadida teve contribuições decisivas para sua evolução.
}

Revista Brasileira de Direito Internacional, Curitiba, v.8, n.8, jul/dez.2008 
Cabe-nos então questionar o motivo do sucesso dos discursos xenófobos. Para isso utilizaremos algumas idéias do sociólogo Zygmunt Bauman.

\subsection{UNSICHERHEITE A NECESSIDADE DE UM INIMIGO}

Bauman identifica problemas com a política e designa através do termo alemão Unsicherheit a incerteza, insegurança e falta de garantia, palavra esta que ajuda a compreender importantes questões contemporâneas. Sob esse termo ele pretende designar a ansiedade difusa que acomete as pessoas que buscam garantias e não conseguem encontrá-la. Ao verem-se impossibilitadas de terem certezas ou garantias a questão em grande medida desloca-se para a segurança, como se ela, unicamente, pudesse resgatar as pessoas da situação em que se encontram. Isso ajuda a explicar o predomínio do discurso da segurança, a imensa divulgação de crimes, e a necessidade de criminalizar o considerado como ameaça - aqui nos referimos à criminalização dos migrantes.

Face a uma ansiedade difusa que provém de medos tão díspares como perder o emprego, perder os laços afetivos, o que expressa medo da solidão, catástrofes, do poder da ciência, e mais recentemente do terrorismo, entre outros medos dificilmente expurgáveis, recorrer à segurança é uma forma de dar uma resposta - ainda que não adequada. ${ }^{27}$

Por isso em momentos de medo coletivo, como o já citado ataque terrorista de 11 de setembro, exigem uma resposta, não para impedir que volte a ocorrer, mas para possibilitar a todos os expectadores das imagens cinematográficas (muitas vezes descritas como surreais) possam ter uma segurança ilusória. No momento de medo que acompanhou o 11 de setembro, e acompanha os eventos traumáticos, as pessoas encontram-se desnorteadas

\footnotetext{
27 "E, enquanto o rancor reprimido, nascido dos medos mais perturbadores por serem difusos e de origem incerta, puder ser lançado sobre um alvo tangível e de modo imediato, não importa muito o fato de que seguir esse caminho dificilmente acabará com a miséria. A estratégia recomendada elimina a tarefa incômoda de fornecer provas de culpa e da premeditacão maligna dos inimigos visados: eles não podem provar sua inocência, já que sua culpa reside em terem sido acusados de forma autorizada, não derivando daquilo que fazem ou pretendam fazer, mas daquilo que são". BAUMAN, Zygmunt. Medo llíquido. p. 150 (grifos nossos).
}

Revista Brasileira de Direito Internacional, Curitiba, v.8, n.8, jul/dez.2008 
e anseiam por alguém que possa conduzi-las à segurança. Neste contexto, Bush foi considerado (por ele mesmo) o commander in chief, e a crítica a uma postura claramente autoritária e falaciosa era tida por anti-patriótica ${ }^{28}$ e por isso rechaçada.

Para Bauman, a transferência das questões reais para questões de segurança funciona do seguinte modo:

às ameaças à segurança, reais ou imaginárias, têm a vantagem de serem concretas, visíveis e palpáveis - vantagem que é encimada e reforçada por outra: a da relativa facilidade de confrontá-las e talvez até derrotá-las. Não admira que essa transferência seja tão comum; não admira também que em consequiência as preocupações populares com a segurança, apelidada 'a lei e a ordem', reduzam o interesse popular produtivo da insegurança e da incerteza e a vontade popular de interromper ou pelo menos refrear sua operação ${ }^{29}$.

Ao deslocar a questão para os migrantes, ou seja, ao eleger o migrante como inimigo, o que se procura é restituir algum alento frente a uma situação sentida como incontrolável. Ademais, procura restituir à política sua oposição fundamental, todavia, ao ser feita essa criação de um inimigo, o campo político é ainda mais esvaziado e deturpado. Quanto aos estrangeiros Bauman escreve:

(...) os governos não podem honestamente prometer aos cidadãos uma existência segura e um futuro garantido; mas podem, por ora, pelo menos eliminar parte da carga de ansiedade acumulada (e até lucrar com isso do ponto de vista eleitoral) demonstrando energia e determinação na guerra contra os estrangeiros à cata de emprego e outros alienígenas arrombadores de portões, intrusos que invadem os quintais nativos outrora limpos, tranqüilos, ordeiros, familiares. ${ }^{30}$

\footnotetext{
${ }^{28}$ Não casualmente, um dos instrumentos que mais simbolizaram a supressão dos direitos individuais e o momento autoritário enfrentado pelos Estados Unidos foi batizado como Ato Patriótico, que autorizava poderes excepcionais ao presidente. Como pretender opor-se, especialmente em um momento de comoção pública, a um ato patriótico? Neste sentido: "O medo, assim parece, geralmente favorece a direita. O nazista Hermann Göring sugeriu àqueles que desejavam aumentar o seu poder, quer numa democracia, quer numa ditadura, que dissessem às pessoas que estavam sendo atacadas, denunciando os pacifistas por falta de patriotismo". STAM, R. Quem tem medo de Donald Rumsfeld?. In: NOVAES, Adauto. (org). Ensaios sobre o Medo. p. 80.

${ }^{29}$ BAUMAN, Zygmunt. Em Busca da Política. p. 56.

${ }^{30}$ BAUMAN, Zygmunt. Em Busca da Política. p. 58. Na continuação deste trecho, Bauman cita o estudo de Phil Cohen acerca da xenofobia entre jovens londrinos. Há menção a um dos entrevistados que tentava definir britanidade de maneira que o incluísse, mas excluísse vários
}

Revista Brasileira de Direito Internacional, Curitiba, v.8, n.8, jul/dez.2008 
Mais do que um complô de políticos ou algo do gênero, uso da relação amigo/inimigo para construir um inimigo identificável com os estrangeiros demonstra o quanto a política está combalida e os direitos historicamente conquistados estão em risco - não só os direitos do outro, do estrangeiro, mas de todos, pois a lógica da lei e ordem tende a se perpetuar e se ampliar. No próximo item analisaremos algumas das conseqüências deste discurso.

\section{COMO O INIMIGO DEVE SER TRATADO}

A partir do momento em que o inimigo é identificado ou construído, há a necessidade de tomar algumas medidas para extirpar seu potencial de danos à comunidade. Isto significa que o inimigo deve ser neutralizado, ou então, no plano mais radical, deve ser eliminado. Entendemos que embora o discurso do inimigo esteja presente no âmbito político, as suas conseqüências não são facilmente aceitas, ao contrário, são tratadas de uma forma eufemística. Logo, as derivações do discurso do estrangeiro como inimigo não é associada à xenofobia ou mesmo à questão do inimigo, mas apresentada como mero resultado dos destemperos dos próprios migrantes. A seguir apresentaremos alguns fatos que podem demonstrar o esforço político em segregar a população migrante.

\subsection{CAMPOS $^{31}$ - ESPAÇOS DE NORMALIDADE EM UMA LÓGICA POLÍTICA ANORMAL.}

Giorgio Agamben, filósofo italiano, retoma o pensamento de Carl Schmitt para ultrapassá-lo e conferir novos significados a sua idéia de exceção enquanto constitutiva da ordem jurídica. Embora o estudo do estado de

grupos de pessoas. O que Bauman aponta com este exemplo é que imersas em um mundo inóspito as pessoas tentam se sentir parte de algo maior - no caso de John a britanidade - e para isso precisam excluir outros. Novamente vemos a lógica do amigo-inimigo sendo usada de forma clara como forma de um consolo impossível.

${ }^{31}$ Embora existam diferentes tipos de campos na política migratória - como exemplos citamos os para aguardar deportação, os para proibir o ingresso, os em que se aguarda a autorização para ingresso, entre outros - neste trabalho os tratamos com a denominação de "campos de estrangeiros" por considerarmos que independente da função alegada todos funcionam de acordo com a mesma lógica. Para saber mais consultar: www.migreurop.org.

Revista Brasileira de Direito Internacional, Curitiba, v.8, n.8, jul/dez.2008 
exceção não seja o objetivo do presente trabalho, teceremos alguns breves comentários para tratar de sua concepção de campos enquanto matriz da política moderna.

Agamben inicia sua análise dos campos definindo-os como o espaço onde a mais profunda condição humana é realizada ${ }^{32}$. Dessa maneira saem do conceito tradicional que define somente os campos utilizados pelos nazistas embora estes claramente sejam os exemplos mais extremos de campos. Mas o que deve ser ressaltado é que os campos estão disseminados na política moderna, especialmente para tentar isolar populações tidas como riscos, ou mesmo, inúteis.

Agamben em sua trajetória em busca da compreensão da política moderna recusa a idéia simplista de explicar fatos inexplicáveis como simples aberrações. Ao contrário, ao estudar eventos excepcionais pretende demonstrar que a exceção tornou-se regra - em concordância com a tese de Walter Benjamin. E neste contexto podemos compreender seu esforço de não negar os eventos ocorridos nos campos, mas visualizá-los como matriz da política que ainda vivemos.

Aceitar o campo como matriz da política moderna significa aceitar que todo espaço onde a mera vida nua é apreendida (em oposição à vida política, tal como entendida para os gregos) e não há lei aplicável é um campo. Embora possa parecer um exagero este conceito permite delinear que os campos de estrangeiros que existem nos aeroportos, e em fronteiras em geral, é um espaço onde a única lei aplicável é a da vida biológica. E a partir disso pode ser revelada a sombra oculta dos discursos de segurança que penalizam os migrantes: estes são vidas biológicas que podem facilmente ser tornados os inimigos tão ansiados. $O$ espaço Schengen $^{33}$ - que quase se confunde com a União Européia - demonstra o interesse não só de afastar os estrangeiros de seu território, mas de em última análise neutralizá-los, circunscrevê-los em um espaço onde seu potencial de risco seja dissipado até ser reduzido ao que é:

\footnotetext{
${ }^{32}$ AGAMBEN, Giorgio. What is a Camp? In: Means Without End: notes on politics. p. 37.

${ }^{33}$ Espaço Schengen é um espaço de cooperação entre alguns países europeus que permite a circulação facilitada de habitantes, ao tempo em que torna mais difícil o ingresso e circulação de pessoas de outros países.
}

Revista Brasileira de Direito Internacional, Curitiba, v.8, n.8, jul/dez.2008 
uma vida inútil e indesejável. Mas os campos não se reduzem à União Européia, ou aos países desenvolvidos. A novidade é que a parceria em função do afastamento desses seres indesejados chega aos países "exportadores", tornando a barreira ainda mais difícil de ultrapassar. Isso pode ser observado na chamada África Branca onde há campos de estrangeiros e medidas altamente inibitórias da migração não-documentada formando uma verdadeira barreira de contenção, separando de forma quase total a pobreza africana das sonhadas benesses européias ${ }^{34}$.

Embora a aceitação de estrangeiros no território nacional seja ato de soberania, o que explica que estrangeiros que cumpriram todas as condições de ingresso sejam mantidos em campos dentro de aeroportos sem qualquer tipo de informação? Poder-se-ia dizer que as políticas de segurança têm funções mais relevantes do que informar estrangeiros barrados, mas ainda assim, o que explica que um dos primeiros atos nestes casos seja o de confiscar todos os produtos de higiene e separar da bagagem ${ }^{35}$ Não parece ser, ao invés de uma casualidade cruel, um ato premeditado de fazer o estrangeiro entender o que ele é naquele país: um outro incivilizado e selvagem?

Paradoxalmente, a mesma lógica do campo, ou seja, a da biologização do homem e conversão da política em biopolítica, ocorre com espaços pretensamente destinados à proteção. Referimo-nos aos campos de refugiados $^{36}$.

A razão de ser de tais campos é a proteção de massas de pessoas que por algum motivo (normalmente guerras) tiveram que deixar suas casas e

\footnotetext{
${ }^{34}$ Para Crépeau e outros, isso expressa uma tendência européia de querer zonas de nãodireito à margem dos estados de direito. ATAK, Idil; CRÉPEAU, François; NAKACHE, Delphine. Sécurité et Droits de la Personne au Canada et en Europe: un déséquilibre à corriger. É o mesmo raciocícnio feito pelos Estados Unidos quando entregam suspeitos para outros países, que sabidamente os torturarão. O discurso de "no nosso território não" é duplamente eficiente, pois alcança o objetivo político e aplaca os dissensos colocando a culpa em países outros.

${ }^{35}$ Conforme relatos de estrangeiros barrados em aeroportos, especialmente nos aeroportos espanhóis.

${ }^{36}$ Aqui mais uma vez referimo-nos ao pensamento de Hannah Arendt que considerava que no contexto pós-guerra o que o mundo tinha a oferecer ao estrangeiro era o campo. Para os amigos o campo de internamento e para os inimigos o campo de concentração. Ambos os campos demonstram a mesma coisa: a profunda superfluidade de massas inteiras. Ou seja, a possibilidade mesma de serem eliminados. LAFER, Celso. A Reconstrução dos Direitos Humanos: um diálogo com o pensamento de Hannah Arendt.
}

Revista Brasileira de Direito Internacional, Curitiba, v.8, n.8, jul/dez.2008 
partir. Como não há possibilidades de colocar milhares (ou milhões, dependendo o caso) de pessoas em outro(s) país(es) de um momento para o outro, constroem-se esses espaços onde sob a proteção de algum organismo internacional busca-se garantir a sobrevivência da população até que seja possível retornar - se for possível retornar. Nesse ínterim fornece-se uma ração diária de alimentação que fornece o mínimo de calorias necessárias para a sobrevivência.

Embora se possa contrapor os campos para proteção daqueles para impedir o ingresso no país, ambos têm a mesma função, excluir os que não merecem ser considerados nacionais, tampouco ser protegidos como tal. Os campos para refugiados, em sua boa-fé, mostram que proteger e segregar podem ser duas faces da mesma moeda.

\subsection{LEGISLAÇÕES MAIS RESTRITIVAS. ESTUDO DA LEGISLAÇÃO DA UNIÃO EUROPÉIA}

Embora tenhamos citado com exemplo a legislação da União Européia dentre outros motivos por ser mais recente e do fato deste bloco preocupar-se com a defesa dos direitos humanos, aquela não é um caso isolado. Ao contrário, a maior parte dos países desenvolvidos têm legislações mais restritivas depois do 11 de setembro tanto para acusados de terrorismo (que em muitos casos não precisa ter acusação formal para possibilitar a detenção) quanto para migrantes indocumentados. Mas a pressão por mudanças legislativas para endurecer o controle das fronteiras afeta também países que servem como ponto de partida dos migrantes. De uma forma sucinta, há cada vez mais pressão para o fechamento das fronteiras, e fechamento não é simplesmente forma figurada, mas concreta, como pode ser visto na criação do muro de $1100 \mathrm{~km}$ entre o México e os Estados Unidos. O que não deixa de ser curioso, pois na queda do muro de Berlim a construção de outros muros foi necessária em uma tentativa de manter o âmbito político longe de crises ${ }^{37}$.

\footnotetext{
${ }^{37}$ Outro exemplo não eufemístico sobre separação/exclusão após o Muro de Berlim pode ser encontrado no Muro do Apartheid, assim nomeada a divisão feita entre Israel e os assentamentos palestinos. Embora a construção venha desde 1967, atualmente têm
}

Revista Brasileira de Direito Internacional, Curitiba, v.8, n.8, jul/dez.2008 
Antes de abordarmos a legislação da União Européia, citaremos alguns outros casos, como o do Canadá. Neste país, há grande pressão norteamericana para recrudescer as medidas migratórias. Em nome da segurança há $l \mathrm{ei}^{38}$ que além de punir o transportador de pessoas sem documentos (inclusive companhias aéreas ou de transportes regulares), prevê que um agente possa prender e deter um estrangeiro se há motivos razoáveis para supor que não é autorizado no território. Tudo sem ordem judicial. ${ }^{39} \mathrm{Ou}$ seja, a política de segurança contra o estrangeiro consegue minar conquistas históricas, como a mais básica, a de possibilidade de defesa.

Em resumo, as leis mais restritivas - e aqui nos referimos especialmente a lei canadense - atuam tornando mais fácil a detenção (muitas vezes por tempo indeterminado), reduzem o auxílio legal (o que é particularmente relevante haja vista a dificuldade de entender as leis nacionais e arcar com os custos legais), imputação excessiva de penas aos que auxiliam os migrantes, não só a ingressar ao país, mas em qualquer momento. Embora esta última previsão seja pautada no argumento de prevenção de tráfico de migrantes, há que ser diferenciado tráfico de auxílio ao ingresso, o primeiro é um crime e realmente deve ser punido, mas o segundo só justifica punição enquanto forma de coibir qualquer forma de auxílio que possibilite o ingresso e permanência do migrante ${ }^{40}$.

Depois destas considerações iniciais abordaremos a legislação da União Européia sobre o tema, aprovada em junho de 2008. A aprovação foi possível graças a uma aliança entre conservadores e liberais e às divisões do grupo socialista. ${ }^{41}$ A lei procura uniformizar o tratamento aos migrantes, especialmente no tocante ao reenvio. Para isso prevê banimento de até 5 anos

\footnotetext{
incorporado mais e mais assentamentos ao Estado de Israel. KLEIN, Naomi. Doutrina de Choque. p. 514. Outras construções são muros de alta tecnologia construídos na fronteira entre a Índia e Caxemira, entre Arábia Saudita e o Iraque, entre o Afeganistão e o Paquistão. p. 519.

${ }^{38}$ Lei sobre imigração e proteção de refugiados, no original Loi sur l'immigration et la protection des refugies.

${ }^{39}$ ATAK, Idil; CRÉPEAU, François; NAKACHE, Delphine. Sécurité et Droits de la Personne au Canada et en Europe: un déséquilibre à corriger.. p. 32.

${ }^{40}$ Ver o trabalho de Crépeau e Nakache. Controlling Irregular Migration in Canadá: Reconciling Security Concerns with Human Rights Protection. Disponível em: www.irpp.org.

${ }^{41}$ Disponível em <http://www1.folha.uol.com.br/folha/mundo/ult94u413765.shtml>.
} 
para os que se recusarem a voltar a voltar a seu país - já que antes de determinar o reenvio o migrante terá a opção de voltar por sua própria escolha, e o mais importante, até 18 meses de detenção antes da expulsão. Para efeito de comparação, a lei francesa que tornou mais visível a questão das detenções em campos tinha como prazo máximo 32 dias. Embora tenha sido defendida como um marco de proteção aos direitos dos migrantes - pois sete estados da União Européia não tinha período máximo de detenção - a lei demonstra cabalmente a tentativa integrada de bloquear o máximo o ingresso e permanência dos migrantes.

Mas em nenhum lugar o discurso é tão escancarado quanto na Itália. Neste país viu-se algo que não se esperava encontrar em democracias ocidentais, em relação ao poder político e suas imbricações com o poder financeiro. O primeiro ministro Silvio Berlusconi, notoriamente um dos homens mais ricos do país, controla grande parte da mídia italiana, e somadas às redes estatais, têm praticamente um monopólio da informação. Embora seu primeiro governo tenha sido marcado por escândalos políticos, ele voltou a ser eleito com o mesmo discurso xenófobo - nada mais natural para alguém pertencente à dita direita - que atribui aos migrantes a máscara de "exército do mal" e por isso deve ser combatido militarmente. Para isso ele pretende inovar no tratamento dos migrantes, ele propõe criminalizar a migração indocumentada. Isto significa que independente do cometimento de qualquer crime, independente das sanções administrativas competentes, o mero fato de o migrante estar em território italiano já seria suficiente para torná-lo um criminoso $^{42}$. Aqui vemos uma mudança do que Hannah Arendt analisou em Origens do Totalitarismo, que ao discorrer acerca dos apátridas e refugiados notou que ao não ter nenhum direito a única forma de inserir-se no ordenamento era no cometimento de crimes $^{43}$. Agora o trabalho foi minorado, afinal o crime nem precisa ser cometido, basta ingressar no país.

\footnotetext{
42 Disponível em <http://www1.folha.uol.com.br/folha/mundo/ult94u392331.shtml>.

43 "Só como transgressor da lei pode o apátrida ser protegido pela lei". ARENDT, Hannah. Origens do Totalitarismo. p. 320.
}

Revista Brasileira de Direito Internacional, Curitiba, v.8, n.8, jul/dez.2008 
4.2.1 Controle Biopolítico. Acesso Controlado por Instrumentos Biométricos.

Uma das formas que têm sido discutidas e utilizadas como forma de barrar acessos indesejáveis aos territórios são os mecanismos biométricos. Estes são definidos como uso de características psicológicas ou behavioristas para reconhecer ou confirmar a identidade de uma pessoa. ${ }^{44} \mathrm{O}$ uso de imagens faciais, digitais em documentos e dos controles biométricos de uma forma geral têm importante implicação nos direitos de personalidade, pois invadem a esfera pessoal. Além disso, o uso de tais expedientes é muitas vezes discriminatório, pois feito em relação a alguns grupos específicos, como os árabes.

É difícil não identificar problemas com os direitos individuais quando se propõe a gravar cenas públicas (como as gravações feitas nos metrôs de Londres ${ }^{45}$ ) e analisá-las para procurar um risco. Note-se que as gravações ininterruptas geram incontáveis horas que não podem ser analisadas manualmente, mas passam por um tratamento eletrônico que procura sinais característicos para identificar suspeitos. Ou seja, a invasão da esfera pessoal conta com uma grande margem discricionária e de falibilidade.

$O$ uso dos mecanismos biométricos - além dos citados podemos acrescentar o estudo de passaportes "inteligentes", aparelhos de raio X que vêem por baixo da roupa, entre outros - significa simplesmente que contra pessoas que são somente vida biológica, o único meio de barrá-las - ou ao menos o mais eficaz - é usando exatamente isso: a biologia ${ }^{46}$.

O tratamento dado nos aeroportos não é casual, faz parte de uma estratégia cada vez mais usada para barrar aqueles que são considerados inimigos, os migrantes. Na busca por uma segurança irrealizável sacrificam-se

\footnotetext{
${ }^{44}$ Thomas apud Crépeau e Nakache. Sécurité et Droits de la Personne au Canada et en Europe: un déséquilibre à corriger.p. 20.

${ }^{45}$ KLEIN,Naomi. Doutrina de Choque. p. 517.

${ }^{46}$ A respeito das (bio)políticas migratórias dos Estados Unidos Giorgio Agamben protestou renunciando ao cargo de Distinguished Professor da New York University e expressou-se no sentido de não ir à esse país enquanto perdurarem tais políticas.
}

Revista Brasileira de Direito Internacional, Curitiba, v.8, n.8, jul/dez.2008 
direitos e garantias individuais. A busca pela vigilância suprema atinge especialmente estes espaços destinados a barrar pessoas as erradas ${ }^{47}$.

\section{CONSIDERAÇÕES FINAIS}

O que diversos autores - como Chantal Mouffe, Giorgio Agamben e Slavoj Žižek - procuram pensar é sobre a perda do espaço político na atualidade e sobre as possibilidades de recuperação deste espaço. Neste trabalho pretendemos mostrar que quando a política perde sua importância e a técnica, ou poderíamos dizer a mera administração, assume seu lugar, o que ocorre é uma violenta tentativa de recolocar a política no cerne da discussão. Com a conseqüente crise do conceito amigo/inimigo, que para Schmitt é o referencial político por excelência, e a indistinção dos critérios políticos, há a impossibilidade de encontrar um inimigo que realmente seja responsável pelos problemas enfrentados. Com isso surgem os conflitos nacionalistas e o discurso xenófobo sai de alas extremistas para ingressar na arena política dita "séria".

O que todos os autores frisam é que o retorno de situações como as guerras ocorridas na antiga lugoslávia não demonstram um retorno do arcaico, mas as conseqüências da perda do espaço político e sua substituição por conflitos visíveis, especialmente os de nacionalidade, já que representam o outro por excelência. Assim ao invés de representar um retorno do passado, prenunciam eventos futuros - que correm o risco de tornarem-se o paradigma político na Terra.

Embora se possa creditar os atuais discursos xenófobos a um extrema direita, eles devem ser reconhecidos enquanto apoiados por grandes parcelas da população que se sente acuada e procura desesperadamente dar uma face visível ao inimigo. O apoio da população à políticas xenófobas é construída sobre um dos sentimentos mais incontroláveis e eficazes: o medo. Como

47 "Em 2007, nas vésperas da decisão do Super Bowl, (...), todos os trabalhadores do Aeroporto Internacional de Miami receberam treinamento para identificar 'pessoas más, e não apenas coisas ruins', utilizando um sistema psicológico chamado de Reconhecimento de Padrão Comportamental, desenvolvido pela empresa israelense New Age Security Solutions (...)". Grifos nossos. KLEIN. Naomi. Doutrina de Choque. p. 518.

Revista Brasileira de Direito Internacional, Curitiba, v.8, n.8, jul/dez.2008 
Orwell escreveu em $1984^{48}$ nada mais eficaz para garantir um regime (seja ele democrático ou não) do que instaurar e alimentar o medo de um outro. Outro que pode ser exterior à comunidade, mas deve ser fomentado para que cada dissidência interna seja vista como um auxílio ao inimigo. $O$ fato de que o outro não exista ou exista, mas não ameace, é positivo, pois permite moldá-lo aos mais diversos medos, dependendo do momento ${ }^{49}$.

Reconhecer o atual ocaso da política significa identificar os discursos manipuladores, assim como pensar novas formas do exercício da política, que fujam da imposição de uma cultura da segurança e vigilância. Reconhecer o papel da política significa reconhecer a importância da construção histórica dos direitos e com isso fugir de falsos dilemas ${ }^{50}$ colocados na defesa de estado que justifica um esvaziamento cada vez maior do espaço democrático. Pensar criticamente a situação política é uma necessidade para que o cidadão desempenhe papel privilegiado na construção da democracia ao invés de ser feito refém de seus medos.

\section{REFERÊNCIAS}

AGAMBEN, Giorgio. Estado de Exceção: homo sacer, II, I. São Paulo: Boitempo Editorial, 2004.

Editora UFMG, 2002.

Homo Sacer. Poder soberano e vida nua. Belo Horizonte:

\footnotetext{
${ }^{48}$ ORWELL, George. 1984. "O mundo apresentado no romance está dividido em três grandes regiões - Lestásia, Eurásia e Oceania - dominadas por ditaduras mantidas graças ao temor (criado pela propaganda) de um imaginário inimigo externo". Especial Bravo! 100 livros essenciais da literatura mundial, 2007. A grande ironia proveniente deste livro é a utilização da figura do Big Brother (Grande Irmão), que na história é a identificação do ditador, em programa televisivo no qual os participantes ficam "internados" em um local onde são filmados continuamente. A crítica de Orwell é um dos casos que por sua extrema atualidade é desqualificada não por sua negação, mas por sua maximização e posterior consumo.

49 Isto pode ser visto especialmente nos filmes hollywodianos nos quais os vilões são retratados de acordo com o momento histórico, podem ser os russos cruéis, os asiáticos malvados, os latinos suados e armados ou mais recentemente os terroristas (que são estrangeiros). Aparentemente a falta de definição do inimigo levou a um novo tipo de vilão, o não-identificável, pois não tem uma origem e nem um pleito definidos. Símbolo desse novo momento é o filme (e suas continuações) Jogos Mortais.

${ }^{50}$ Referimo-nos especialmente às discussões acerca do direito de torturar ou das mortes de inocentes identificados com terroristas (como o brasileiro Jean Charles morto pela polícia britânica que tentou adulterar fatos da morte para que parecesse culpado) como efeito colateral, mas necessário, para garantia da segurança.
}

Revista Brasileira de Direito Internacional, Curitiba, v.8, n.8, jul/dez.2008 
Means without End. Minneapolis and London: University of Minnesota Press, 2000. 01-45.

ARENDT, Hannah. Origens do Totalitarismo: Anti-Semitismo, Imperialismo, Totalitarismo. São Paulo: Companhia das Letras, 2004.

ARRUDA, José Maria. Carl Schmitt: Política, Estado e Direito. In: AGUIAR, Odílio Alves; OLIVEIRA, Manfredo, SAHD, Luiz Felipes Netto de Andrade e Silva (org). Filosofia Política Contemporânea. Petrópolis: Vozes, 2003.

Association Nacionale d'Assistence aux Frontières pour les Étrangers (ANAFÉ). Disponível em: <http://www.anafe.org/za.php>

ATAK, Idil, CRÉPEAU, François, NAKACHE, Delphine. Sécurite et Droits de la Personne au Canada et en Europe: un déséquilibre à corriger. Disponível em : $<$ www.irpp.org $>$.

BAUMAN, Zygmunt. Medo llíquido. Rio de Janeiro: Jorge Zahar Ed., 2008. . Em Busca da Política. Rio de Janeiro: Jorge Zahar Ed., 2000.

Bravo! Especial. 100 livros essenciais da literatura mundial. Ed. Abril, 2007.

CAMUS, Albert. L'etranger. Paris: Éditions Gallimard, 2005.

CRÉPEAU, François, NAKACHE, Delphine Controlling Irregular Migration in Canadá: Reconciling Security Concerns with Human Rights Protection. Disponível em: <www.irpp.org>.

DUBY, Georges. Ano 1000, ano 2000: na pista de nossos medos. São Paulo: Fundação Editora da Unesp, 1998.

KLEIN, Naomi. A Doutrina de Choque: a ascensão do capitalismo de desastre. Rio de Janeiro: Nova Fronteira. 2008.

LAFER, Celso. A Reconstrução dos Direitos Humanos: um diálogo com o pensamento de Hannah Arendt. São Paulo: Companhia das Letras, 1991.

MIGREUROP: Disponível em <www.migreurop.org>

MOUFFE, Chantal. O Regresso do Político. Lisboa: Gradiva, 1996.

NOVAES, Adauto (org). Ensaios sobre o Medo. São Paulo: Senac São Paulo: Edições Sesc SP, 2007.

Novo Dicionário Eletrônico Aurélio versão 5.11, 2004.

ORWELL, George. 1984. trad. Wilson Velloso. São Paulo: Ibep Nacional. 
SCHMITT, Carl. O Conceito do Político. Petrópolis: Vozes, 1992.

ŽIŽEK, Slavoj. Bem vindo ao Deserto do Real! cinco ensaios sobre o 11 de Setembro e datas relacionadas. São Paulo: Boitempo Editorial, 2003. 